\title{
La autocomunicación absoluta de Dios en sí mismo según Karl Rahner
}

\author{
JORGE AROS VEGA \\ Pontificia Universidad Católica de Valparaíso (Chile) \\ jorge.aros@ucv.cl
}

\begin{abstract}
Resumen
El propósito del artículo es profundizar el carácter absoluto de la autocomunicación de Dios al hombre, lo cual entregará un aporte a la teología actual en lo que se refiere a la comprensión y utilización del concepto de autocomunicación, y a la vez entender de un modo renovado el encuentro entre Dios y el hombre, lo que permitirá hallar nuevas pistas para la entrega del mensaje cristiano al hombre contemporáneo. El escrito aborda el tema en dos tópicos: el primero en razón del Dios absoluto, como fundamento de la autocomunicación y el segundo que trata el carácter trinitario de la autocomunicación absoluta.
\end{abstract}

Palabras clave: auto-comunicación, Dios, absoluto, Trinidad, hombre.

\section{God's absolute self-communication in itself according to Karl Rabner}

\begin{abstract}
The purpose of the article is deepen the absolute nature of self-communication from God to Man, which will give a contribution in actual Theology referring to the comprehension and utilization of the concept of self-communication, and at the same time to understand in a new ay the encounter among God and Man. This will permit to find new clues to the delivery of the Christian message to the contemporary man. The work deals with the matter in with two topics: the first is related with absolute God, as basis of self-communication; and the second one is related to the Trinitarian nature of absolute self-communication.
\end{abstract}

Key words: self-communication, God, absolute, Trinity, Man.

Licenciando en Ciencias Religiosas por el Instituto de Ciencias Religiosas (Ad Instar Facultatis) de la Pontificia Universidad Católica de Valparaíso. Magíster en Teología Dogmática por la Pontificia Universidad Católica de Chile. Profesor del Instituto de Ciencias Religiosas de la PUCV.

Este artículo se basa en la primera parte de la Tesis para optar al grado de Magíster en Teología titulada "El carácter absoluto de la autocomunicación de Dios como clave de lectura del Curso Fundamental sobre la fe de Karl Rahner", presentada en la Facultad de Teología de la Pontificia Universidad Católica de Chile, y que contó con el patrocinio de Stipendienwerk Lateinamerika-Deutshland, a través de su Consejo de Valparaíso. 


\section{Introducción}

El presente artículo desarrolla el tema de la autocomunicación de Dios en el pensamiento de Karl Rahner. Se optó por este tema porque es un eje central en el pensamiento y obra del gran teólogo alemán del siglo $\mathrm{XX}^{1}$. Sin embargo, por la vasta amplitud de la materia propuesta, fue preciso realizar una focalización al acercamiento del término «autocomunicación» (Selbstmitteilung) que permitiera emprender la investigación y que, al mismo tiempo, aportara nuevas luces con respecto al tema y a sus implicancias para los hombres y mujeres de hoy. En este contexto, se hace la opción por el carácter absoluto que Rahner le entrega a la autocomunicación de Dios en su obra Curso fundamental sobre la fe (Grunkurs des Glaubens, 1976).

Es cierto que el concepto de absoluto no goza de gran prestigio en nuestra sociedad contemporánea, pues, como decía el entonces Cardenal Ratzinger en la homilía de la Misa Pro eligendo Pontifice (18 de abril de 2005), «se va constituyendo una dictadura del relativismo que no reconoce nada como definitivo y que deja como última medida sólo el propio yo y sus antojos». Ante esta realidad es osado, en cierto modo, asumir un tema que, en alguna medida, puede verse enfrentado directamente con la experiencia concreta del hombre de hoy. Pero no podemos dejar de mencionar que el carácter absoluto de la autocomunicación de Dios propuesto por Rahner en la obra mencionada no va directamente dirigido a una contraposición con el relativismo, puesto que no es su intención, sino que en la medida que él va planteando el carácter definitivo, único e irrevocable que adquiere la autocomunicación de Dios en el acontecimiento de la encarnación de Cristo se contrapone de una u otra forma a la manera de enfrentar la vida que tiene la sociedad contemporánea ${ }^{2}$.

El objetivo de este artículo es profundizar en el carácter absoluto de la autocomunicación de Dios al hombre, lo cual entregará un aporte a la teología actual en lo que se refiere a la comprensión y utilización del

\footnotetext{
1 Carlos Schickendantz describe tres motivos que llevarían a Rahner a escoger el término Selbstmitteilung (autocomunicación) por el de ungeschaffene Gnade (gracia increada): «una perspectiva más personalista frente a las limitaciones que, de hecho, tiene la palabra gracia; la orientación filosófica de Rahner, de manera que la gracia (Dios mismo) aparece como respuesta a la pregunta que el hombre es estructuralmente; un motivo pastoral, omnipresente en la teología de Rahner», C. SCHICKENDANTZ: "Autotrascendencia radicalizada en extrema impotencia. La comprensión de la muerte en Karl Rahner", Anales de la Facultad de Teología, 50 (1999), 147.

2 Sobre esta realidad contemporánea, véase S. SILVA: "Lo absoluto y lo relativo. Aproximación hermenéutica”, Teología y Vida, 49 (2008), 203-220.
} 
concepto de autocomunicación, para, desde allí, valorar el encuentro entre Dios y el hombre, lo que permitirá hallar en ello nuevas pistas para la entrega del mensaje cristiano al hombre contemporáneo.

Con respecto al método utilizado en este artículo quisiera manifestar que se trata de una forma diversa de presentar el pensamiento de Rahner, pues se ordena el análisis partiendo desde Dios, lo que constituye una diferencia con respecto del autor analizado, ya que su opción es partir más bien desde el hombre ${ }^{3}$. Esta opción se fundamenta en el propósito específico de presentar el carácter absoluto de la autocomunicación de Dios desde la concepción que Rahner manifiesta en su obra. Sin embargo, no podemos dejar de señalar que a pesar de esta opción, no es posible desarrollar un discurso que radique exclusivamente en Dios, puesto que para Rahner los enunciados sobre Dios son, al mismo tiempo, enunciados sobre el hombre y viceversa, donde teocentrismo y antropocentrismo son una única realidad expresada desde dos ángulos diversos, donde una reclama la otra ${ }^{4}$.

El presente artículo se ordenará en dos apartados que tratarán el tema de la autocomunicación absoluta de Dios en sí mismo. El primer apartado se abocará a Dios absoluto como fundamento de la autocomunicación absoluta, y el segundo abordará el tema desde el carácter trinitario de la autocomunicación absoluta.

\section{Dios absoluto, fundamento de la autocomunicación absoluta}

Este primer apartado se sumergirá en el pensamiento de Rahner de cara a precisar el concepto de absoluto para referirse a Dios y en qué sentido lo utiliza en relación al carácter absoluto de la autocomunicación. En un primer momento se abordará la designación Dios absoluto y, en un segundo momento, se describirán tres atributos entregados por Rahner a Dios, a saber: ser absoluto, misterio absoluto y sujeto absoluto.

\subsection{Dios absoluto}

Con respecto a la expresión Dios absoluto, lo primero que hay que señalar, es que Rahner la utiliza en ocho pasajes del Curso fundamental sobre

Con respecto al tema de la metodología en Rahner y su giro antropológico, véase F. BERRÍOS: "El método antropológico-trascendental de Karl Rahner como hermenéutica teológica del mundo y de la praxis", Teología y Vida, 45 (2004), 412-415.

Cfr. F. ARDUSSO et al.: La teologia contemporanea: introduzione e brani antologici. Casa Editrice Marietti, Torino 1980, 420. 
la $f e^{5}$, en ellos se manifiesta la realidad absoluta de Dios para destacar su presencia en la existencia de los hombres ${ }^{6}$. De hecho, en la primera cita encontramos que la designación de Dios absoluto está directamente relacionada con la autocomunicación cuando manifiesta que «La propia oferta de Dios, en la que él se comunica absolutamente a la totalidad del hombre, es por definición la salvación, ya que es la consumación de la trascendencia del hombre, en la que éste se trasciende a sí mismo hacia el Dios absoluto»?

La autocomunicación es la oferta absoluta de Dios hacia el hombre en plenitud, su finalidad es soteriológica, su puerto de llegada es el Dios absoluto. Es decir, el hombre llega a su consumación cuando orienta su trascendentalidad hacia el Dios absoluto, que le ha ofrecido por su propia comunicación un encuentro que será salvífico para él. He aquí una primera realidad que se destaca en el pensamiento de Rahner: el Dios absoluto es el punto de referencia hacia el cual tiende el hombre como ente finito ${ }^{8}$.

Más adelante, en la obra se encuentra una descripción de la manera cómo se hace presente concretamente esta realidad salvífica para el hombre. Rahner muestra al Dios absoluto no como una realidad abstracta y lejana al hombre', sino que lo presenta cercano a la realidad humana, pues por medio de Jesucristo se halla el acceso al Dios absoluto. Así, Rahner presenta a Cristo como el absolutum concretissimum ${ }^{10}$, en cuanto es el que posibilita el encuentro pleno entre Dios y el hombre, además, a

5 Cfr. K. RAhner: Curso fundamental sobre la fe. Herder, Barcelona 1972, 177, 230, 359, 462, 467, 468, 470, 491.

6 Para Rahner que Dios pueda ser designado como absoluto se fundamenta en la revelación bíblica, cfr. K. RAHNER: "Theos en el Nuevo Testamento", en ibíd., Escritos de teología I, Taurus, Madrid 1963, 128.

7 K. RAHNER: Curso fundamental sobre la fe, 177.

8 Según Arzubialde esta experiencia trascendental del hombre es uno de los conceptos claves de todo el sistema rahneriano, cfr. S. ARZUBIALDE: "La experiencia trascendental de Dios en la obra de K. Rahner", Estudios Eclesiásticos, vol. 80, n 313 (2005), 293.

9 En reiteradas ocasiones Rahner afirma la realidad personal de Dios como aquella cualidad que permite esta cercanía con el hombre, esto queda claro cuando señala «Ahora bien, Dios, con ser absoluto, o, mejor dicho, por serlo, no es algo impersonal, no es un punto fijo asintótico en que se refugia la trascendencia de la persona espiritual, sino el 'Dios vivo'», K. RAHNER: "Culpa y perdón de la culpa como región fronteriza entre la teología y la psicoterapia", en ibíd., Escritos de Teología II, Taurus, Madrid 1963, 290.

10 Cfr. K. RAHNER: Curso fundamental sobre la fe, 359. 
partir de la singularidad divina de Jesucristo, el hombre comprende su propia singularidad ${ }^{11}$.

De este modo, la autocomunicación de Dios de ninguna manera se presenta como una oferta general e impersonal y que, por lo mismo, no compromete a nadie; sino que más bien es una realidad que atañe a cada hombre en su existencia más íntima. Para Rahner la forma concreta de realización de esta comunión son los sacramentos, los cuales para él son una instancia de diálogo y asociación entre Dios y el hombre ${ }^{12}$.

La mediación sacramental se hace esencialmente necesaria, puesto que entre el Dios absoluto y la creatura se da una diferencia radical que sólo es subsanada por la intervención divina, ya que por medio de los sacramentos dona su gracia al hombre, atrayéndolo hacia sí, de modo que lo capacita tanto para el encuentro como para la respuesta que ha de dar a la oferta hecha por Dios en la autocomunicación absoluta ${ }^{13}$. De este modo, Dios con su poder absoluto es el que permite el acercamiento del hombre hacia él, situación que es de suyo imposible para el hombre como ente finito. Esta condición de sociedad asimétrica acompañará permanentemente la comprensión de la relación entre Dios y el hombre ${ }^{14}$.

11 García Murga, comentando los aspectos nucleares del pensamiento de Rahner, señala: «Quien acoge la historia de Jesús, y la historia de la humanidad en Jesús y con Jesús, acepta la cercanía del Misterio Santo de Dios, y la voluntad del Padre de comunicarnos su propia Vida, convirtiendo a los seres humanos en hijos suyos en su propio Hijo», J. R. GARCÍA-MURGA: "Fiel a la tierra, desbordado y acogido por el misterio. Lo nuclear cristiano según Karl Rahner”, Estudios Eclesiásticos, vol. 80, n 313 (2005), 425.

12 En este punto hay que señalar que no es extraño en el pensamiento de Rahner unir los sacramentos con Jesucristo, ya que, como señala Ignazio Sanna, la concepción rahneriana de los sacramentos posee una estructura encarnatoria, cfr. I. SANNA: Karl Rahner. San Pablo, Madrid 2006, 68-69.

13 Karen Kilby se cuestiona la forma cómo Rahner escribe sobre los sacramentos a la luz de su interpretación absolutamente universal de la gracia. Este aspecto lo resuelve planteando que para Rahner los sacramentos no sólo simbolizan la gracia y la causan, sino que más bien se trata de que causan la gracia precisamente al simbolizarla; cfr. K. KILBY: Introducción a Karl Rabner. Mensajero, Bilbao 2009, 59-61. También, cfr. K. RAHNER: "Consuelo del tiempo", en ibíd., Escritos de Teología III. Taurus, Madrid 1961, 169-170.

14 Son iluminadoras las palabras de Rahner que reproduce Vorgrimler, cuando señala que: «Dios es el Absoluto, el Incondicionado al que nosotros nos hallamos vinculados, mientras sabemos que él no se encuentra vinculado con nosotros de esa misma forma», H. VORgrimLER: Karl Rahner. Experiencia de Dios en su vida y en su pensamiento. Sal Terrae, Santander 2004, 176-177. 


\subsection{Atributos absolutos de Dios}

Ahora corresponde describir tres atributos absolutos con los cuales Rahner designa a Dios en el Curso fundamental sobre la fe, a saber: el ser absoluto, misterio absoluto y sujeto absoluto.

\subsubsection{Ser absoluto}

Esta expresión aparece catorce veces en el texto ${ }^{15}$. Mediante ella Rahner manifiesta que la autocomunicación de Dios al hombre, sólo es posible si él es ser absoluto $^{16}$. Esto permite que dicha autocomunicación se realice, ya que Dios puede donarse y crear aquello que es distinto de él y se mantiene como él mismo sin perder ninguna de sus cualidades; junto con lo anterior, él puede sostener y propiciar desde sí su relación con el hombre y, en ello, queda confirmado que él es el Ser absoluto que sostiene toda la realidad ${ }^{17}$. En este encuentro de Dios con el ente finito, el ser absoluto se presenta como aquel motor que despierta el movimiento del ente finito hacia sí y se constituye en el soporte más íntimo de la relación que se establece entre el ente finito y el ser absoluto $^{18}$.

En esta perspectiva, no es de extrañar que Rahner plantee que la relación que se da entre Dios y la creatura es de dependencia, no de Dios hacia la creatura sino de la creatura hacia Dios: «Esta dependencia radical tiene que ser duradera, o sea, no ha de afectar sólo al momento de un comienzo, pues lo finito remite ahora y siempre a lo absoluto como su fundamento» ${ }^{19}$. Dicha dependencia radica en que el ente finito participa

15 Cfr. K. RAHNER: Curso fundamental sobre la fe, 53, 83, 92, 98, 99, 102, 150 (2), 153 (3), 154, 210, 224.

16 Sergio Silva señala que si hay algo que merece el nombre de absoluto es Dios, hasta el punto que afirmar que Dios es absoluto es una tautología, el problema está en cuál es la imagen que el hombre tiene de Dios, cfr. S. SILVA: "Lo absoluto y lo relativo. Aproximación hermenéutica”, 219.

17 Cfr. K. Rahner: "La comunicación de Dios mismo al hombre" (voz "Dios"), en K. Rahner (dir.), Sacramentum Mundi II, Herder, Barcelona 1976², 345.

18 Según Cabada: «Rahner habla en este sentido de la divinidad como el 'hacia dónde' (Woraufbin) o también —en la etapa más madura de su pensamiento- del 'de-dónde' (Wovonher) de la experiencia trascendental del hombre, expresiones ambas que no hacen referencia a un 'objeto' entre los objetos, sino más bien al " 'horizonte', condición de posibilidad del conocimiento objetual", y al fundamento posibilitante de las experiencias antropológicas básicas de la voluntad y la libertad», M. CABADA: El Dios que da que pensar: acceso filosófico-antropológico a la divinidad. Biblioteca de Autores Cristianos, Madrid 1999, 85.

19 K. RAHNER: Curso fundamental sobre la fe, 103. 
del ser por donación, el ser absoluto se convierte, de este modo, en el fundamento que soporta la existencia del ente finito y en ello radicaría la esencia ontológica de la autocomunicación.

Ahora bien, por ser la autocomunicación una posibilidad real de encuentro entre Dios y el hombre, este último, según Rahner, puede reconocer los atributos absolutos de Dios, porque es una persona espiritual. En esta condición, cada acción que realiza le hace presente el ser absoluto como fundamento real de su existencia y, al mismo tiempo, como inabarcable para él, por eso no es extraño que perciba a Dios como misterio absoluto ${ }^{20}$. Desde aquí se pueden desprender dos aspectos importantes en el pensamiento de Rahner, lo primero es que esta realidad absoluta entrega un horizonte para el encuentro espiritual; y, al mismo tiempo, permite comprender que lo absoluto no emerge de una posibilidad creativa del sujeto finito, sino que es una realidad que se hace presente en su propia existencia ${ }^{21}$.

Es en esta perspectiva donde se puede comprender mejor que en dicho encuentro Dios siempre se presenta como un misterio inabarcable para el ente finito ${ }^{22}$. Al respecto, Rahner señala que «Autocomunicación divina significa, por tanto, que Dios puede comunicarse a sí mismo como sí mismo a lo no divino, sin dejar de ser la realidad infinita y el misterio absoluto, y sin que el hombre deje de ser el ente finito, distinto de $\operatorname{Dios}{ }^{23}$.

Así, pues, la autocomunicación se presenta como un encuentro de Dios con el hombre, al que cada uno concurre con su ser total, situación que transforma profundamente a este último, pero que no por ello ha de comprenderse como absorción en el ser absoluto de Dios, ya que cada cual sigue siendo distinto en su ser: el hombre sigue siendo hombre y Dios sigue siendo Dios ${ }^{24}$.

20 Cfr. K. RAHNER: "Sobre el concepto de misterio en la teología católica", en ibíd., Escritos de Teología IV. Taurus, Madrid 1963, 82-83.

21 Cabada es enfático en señalar que la experiencia del Absoluto está presente en la vida del ser humano como una realidad que le posibilita referirse a él. Además, señala una serie de pensadores que han abordado el tema en este mismo sentido, tales como Bernardo de Claraval, Nicolás de Cusa, Pascal, Schelling, Hegel y Scheler, cfr. M. CABADA: "La vivencia previa del absoluto como presupuesto del acceso teorético a Dios", en Teología y mundo contemporáneo: homenaje a K. Rahner en su 70 cumpleaños. Cristiandad, Madrid 1975, 71-72.

22 Cfr. K. RAHNER: "Para la teología de la encarnación", en Escritos de Teología IV. Taurus, Madrid 1963, 146.

23 K. RAHNER: Curso fundamental sobre la fe, 151.

24 Es interesante constatar que en la reflexión teológica actual se ve muy presente este aspecto que Rahner destaca. Al respecto Adolphe Gesché señala: «Dios, el Otro de los hombres, constituye muy exactamente esta alteridad que me permite identificarme y 


\subsubsection{Misterio absoluto}

El tema de Dios como misterio absoluto es ampliamente tratado por Rahner principalmente en el Grado segundo, titulado El hombre ante el Misterio Absoluto, y habría que señalar que el término aparece treintaicuatro veces a lo largo de la obra ${ }^{25}$. Por su parte, cuando Rahner aborda el tema, entrega una definición que a simple vista permite comprender qué es lo que entiende cuando se refiere a Dios con este término, diciendo:

Mediante esa autocomunicación no se suprime o niega lo dicho antes sobre la presencia de Dios como el misterio absoluto y esencialmente inabarcable. También en la gracia y en la inmediata visión divina, Dios sigue siendo Dios, es decir, la medida primera y última que con nada puede medirse; sigue siendo aquel misterio que es lo único inteligible por sí mismo; el hacia dónde de la acción suprema del hombre, el hacia dónde que posibilita y sustenta por sí mismo esta acción; Dios sigue siendo el santo, que sólo es accesible realmente en la adoración; Dios permanece el absolutamente innominado e inefable, el cual nunca puede comprenderse, ni siquiera por su propia comunicación en la gracia y en la visión inmediata; sigue siendo el no sujeto al hombre, el que nunca puede enmarcarse en un sistema humano de coordenadas del conocimiento y de la libertad ${ }^{26}$.

Para Rahner, en la autocomunicación es Dios mismo quien se dona al hombre, sin embargo, esto no permite asumir que el hombre puede acoger en su totalidad dicha donación. En esta circunstancia, se asume a Dios como misterio absoluto para el hombre, puesto que a pesar de esta donación y de la gracia que ello supone como ayuda para la recepción de esta oferta absoluta, siempre queda un espacio en el que Dios sigue siendo el misterio inabarcable. En este contexto, Rahner da una serie de apelativos a Dios, y con ello intenta manifestar su grandeza inalcanzable, con lo que deja de manifiesto que lo considera como absoluto ${ }^{27}$.

no perderme en aquello que no es nunca más que yo o que, tratándose del otro (con una 'o' minúscula), termina siempre por convertirse en un reflejo de mí mismo», A. GESCHÉ: El sentido. Ediciones Sígueme, Salamanca 2004, 77-78.

25 Cfr. K. RAHNER: Curso fundamental sobre la fe, 65 (2); 74; $76 ; 77$ (2); 91 (2); 96; 98; $105 ; 108 ; 126 ; 148 ; 150 ; 151$ (2); 152; 154; 162; 199; 203; 208; 220 (2); 221; 258; 259; $263 ; 359 ; 362 ; 458 ; 459 ; 513$.

26 K. RAHNER: Curso fundamental sobre la fe, 151.

27 Cfr. K. RAHNER: "Sobre el concepto escolástico de la gracia increada", en ibíd., Escritos de Teología I. Taurus, Madrid 1963, 363-364. En lo referente al tema del misterio, en el pensamiento de Rahner, Ignazio Sanna lo presenta como una paradoja en la relación entre Dios y el hombre: «relación con Dios considerado como lejanía y relación 
Desde aquí, se pueden desprender algunas cualidades del absoluto que Rahner emplea para referirse a Dios y que son claves al momento de precisar el carácter absoluto de la autocomunicación. Entre otras encontramos su no dependencia y no referencia a otro ser; luego manifiesta que es un ser que subsiste por sí mismo, pues no necesita de otro para comprenderse; más adelante se puede apreciar que presenta al absoluto como el motor inmóvil que genera todo movimiento y, también, lo presenta como el que trasciende la realidad humana y llama a su encuentro; después manifiesta la separación absoluta que existe entre Dios y el hombre, pues a éste le queda sólo la adoración como medio de encuentro con el absolutamente santo; luego presenta la incapacidad de las palabras humanas para expresar la realidad del absoluto, es decir, para el ente finito la comprensión del ser absoluto le resulta un trabajo dificultoso y que, no pocas veces, llega a su fin pues es imposible que el absoluto pueda reducirse hasta la comprensión plena del ente finito ${ }^{28}$.

Sin embargo, Rahner plantea que para el hombre existe un camino de acceso a la comprensión del misterio absoluto, éste es la donación que Dios hace de sí mismo por medio de la autocomunicación, que se presenta como un verdadero «des-ocultamiento de Dios como el permanente misterio absoluto ${ }^{29}$. A partir de ello, el hombre puede acceder de modo certero a aquella realidad que lo sobrepasa y que escapa a todas sus percepciones, pues es Dios quien crea y, creando, viene al encuentro del hombre y se hace cercano a él, para que éste pueda reconocerlo a pesar de que su realidad profunda sigue siendo un misterio absoluto inabarcable por el intelecto humano ${ }^{30}$.

\subsubsection{Sujeto absoluto}

Con respecto a este atributo hay que señalar que Rahner reconoce a Dios como el sujeto absoluto, no porque así lo mencione en el Curso

con Dios considerado como la proximidad que se comunica a sí misma», I. SANNA: Karl Rabner, 163.

28 Con respecto a la idea del misterio incomprensible, Ángel Cordovilla sostiene que a la base de este pensamiento rahneriano está la espiritualidad ignaciana, cfr. A. CORDOVILLA: "K. Rahner, la actualidad de un teólogo", Estudios Eclesiásticos, vol. 80, n 313 (2005), 239.

29 K. RAHNER: Curso fundamental sobre la fe, 151-152.

30 K. RAHNER: "La comunicación de Dios mismo al hombre" (voz "Dios"), en K. Rahner (dir.), Sacramentum Mundi II, Herder, Barcelona 1976², 343-348. En este sentido es necesario poner de manifiesto que en el pensamiento de Rahner la creación es la primera instancia de la autocomunicación, por la cual Dios se dice y se da a la creatura, cfr. A. CORDOVILLA: "La teología es pensar. La relación entre teología y filosofía en K. Rahner”, Estudios Eclesiásticos, vol. 79, nº 310 (2005), 397. 
fundamental sobre la fe, sino porque cada vez que él utiliza este término lo hace en el sentido de afirmar que al hombre le está vedado asumirse como sujeto absoluto.

Para Rahner el hombre, desde su trascendentalidad se auto-reconoce como sujeto, pero no puede tener la pretensión de ser el sujeto absoluto, ya que dicho enunciado está referido más bien a aquel que le ha entregado el ser. El hombre experimenta en su propia trascendencia el vacío que implica no ser él quien se da a sí mismo el ser, sino que proviene de Otro, por lo que puede reconocer que su existencia se funda en el misterio ${ }^{31}$.

Desde la exposición que Rahner hace sobre al tema de la trascendentalidad del hombre, se puede desprender que sujeto absoluto es aquel que es el Ser absoluto y el Misterio absoluto, es decir, Dios mismo. Esto se aprecia claramente cuando, refiriéndose a la creadora causalidad eficiente de Dios, expresa que ella «en el fondo ha de pensarse sólo como una modalidad o un modo eficiente de aquella absoluta y tremenda posibilidad de Dios consistente en que él —el amor en persona, el sujeto absolutamente feliz y consumado en sí mismo-, puede comunicarse a sí mismo a otro» ${ }^{32}$.

De esta forma, Dios es presentado como el sujeto consumado en sí mismo, es decir, que subsiste por sí mismo y que posee atributos absolutos como la felicidad. Todo esto permite reconocerlo como sujeto absoluto que posee la capacidad de comunicarse a sí mismo al otro, al ente finito, que hallará en este encuentro su consistencia más plena ${ }^{33}$.

31 En el pensamiento antropológico de Rahner el ser humano es el sujeto de la trascendentalidad ilimitada, pero no por eso es sujeto absoluto, cfr. I. SANNA: Karl Rabner, 160.

32 K. RAHNER: Curso fundamental sobre la fe, 154.

33 Hoy se da una concepción de absoluto que se autodespliega o automanifiesta, ya sea de forma lógico-metafísica, ya sea temporalmente, cfr. J. FERRATER MORA: Diccionario de Filosofía. Sudamericana, Buenos Aires 19584, 24. En este sentido, el pensamiento de Hegel puede ser iluminador, puesto que para él lo absoluto es «el espíritu, que sale de sí, se exterioriza, se aliena en la naturaleza como en su otro y en la historia vuelve a encontrarse a sí mismo en el saber absoluto, en cuyo "resultado" es donde lo absoluto es verdaderamente absoluto», M. MÜLler y A. HALDER: Breve Diccionario de Filosofía. Herder, Barcelona 1981, 12. Rahner también presenta esta concepción, en cuanto al absoluto que se autodespliega fuera de sí, cfr. K. RAHNER: "Naturaleza de la Gracia, III. Exposición teológica", en K. Rahner (dir.), Sacramentum Mundi III, Herder, Barcelona 1976², 320. 


\section{El carácter trinitario de la auto-comunicación absoluta}

Ahora toca dar una mirada al carácter trinitario de la autocomunicación precisando, primeramente, la dimensión personal de Dios. Para, en un segundo momento, presentar la participación de cada una de las personas de la Trinidad en la autocomunicación.

\subsection{Dimensión personal del Dios absoluto}

Para tratar la dimensión personal del Dios absoluto lo primero que parece conveniente es precisar de qué forma la concepción de Dios como persona aporta nuevas luces en la comprensión del desarrollo de la autocomunicación de Dios hacia el hombre. En este sentido, Rahner es enfático al manifestar que «La afirmación de que Dios es persona, de que él es un Dios personal, pertenece a las afirmaciones fundamentales cristianas sobre Dios» ${ }^{34}$.

Esta afirmación, central en el cristianismo, es determinante puesto que no se habla de un Dios impersonal, en cuanto es presentado simplemente como una energía que sustenta todo; sino, por el contrario, se trata de un Dios que es persona, y que, bajo esta condición, entra libremente en relación con el hombre ${ }^{35}$.

La realidad de este Dios personal, a la que Rahner le atribuye un carácter absoluto y una libertad absoluta, es analogada con la dimensión de Dios como ser absoluto y sus características de fundamento, misterio y horizonte; ambas denominaciones, persona y libertad absolutas, son realidades que el autor considera obvias. Sin embargo, a pesar de afirmar con tanto énfasis que Dios es persona, Rahner no desconoce que esta aseveración presenta para los hombres de nuestro tiempo una serie de dificultades en su comprensión, aspecto que destaca a la hora de hacer mención al uso profano del lenguaje cuando se utiliza el concepto de persona. Este aspecto no es menor, puesto que según Rahner dicha

\footnotetext{
34 K. RAHNER: Curso fundamental sobre la fe, 97.

35 Al respecto, Michael Schulz señala que en su argumentación, sobre la realidad personal de Dios, Rahner se apoya en el método de Kant, pero intentando atravesar los límites epistemológicos planteados por Kant, desde allí desarrolla diversos argumentos para describir la realidad personal de Dios. Cfr. M. SCHULZ: "La necesaria mediación filosófica de la fe y de la teología según Karl Rahner", Estudios Eclesiásticos, vol. 80, 313 (2005), 330-334. También, cfr. K. RAHnER: Oyente de la palabra. Herder, Barcelona $1967^{2}, 116$.
} 
utilización del vocablo no es adecuada para hablar de las personas trinitarias ${ }^{36}$.

En este sentido, Rahner nos pone en alerta con respecto a la costumbre de designar sencillamente a Dios como persona en medio de la experiencia de fe, pues:

cabe preguntar si Dios de suyo puede llamarse persona, y podemos preguntar también si Dios es persona sólo frente a nosotros y si en relación con nosotros se oculta en su absoluta lejanía trascendente. Entonces ciertamente deberíamos decir que Dios es persona, mas por ello no asumiría ni de lejos aquella relación personal con nosotros que presuponemos en nuestra conducta religiosa, en la oración, en nuestra conversión creyente, esperanzada y amorosa a $\operatorname{Dios}^{37}$.

Salta a la vista que, para Rahner, la mayor parte de las veces se olvida que el término persona no posee en su explicación última una definición unívoca $^{38}$; en un segundo momento, llama a reflexionar en torno a que el reconocimiento de Dios como persona no garantiza al hombre una relación personal con Dios, pues por su ser absoluto podría mantenerse alejado de la relación con el ser humano. Es aquí donde la autocomunicación asume un rol fundamental en el pensamiento de Rahner, al momento de resolver la disyuntiva planteada.

Para Rahner, Dios mismo, a través de la autocomunicación, se hace el encontradizo con el hombre, desde su propia realidad de misterio personal y absoluto, sólo así va al encuentro de otro ser que también es espiritual y personal ${ }^{39}$. La certeza de esta relación personal, entre Dios y el hombre, radica en el hecho que lo comunicado por Dios es él mismo, no es una realidad ajena a él, por tanto, esta comunicación produce en el hombre una transformación profunda, ya que Dios se convierte en el constitutivo más íntimo del ser humano ${ }^{40}$. Por eso Rahner designará a la

36 Rahner precisa claramente esta dificultad del uso contemporáneo del concepto persona en relación con la doctrina trinitaria en otras obras, al respecto, cfr. K. RAHNER: "Dios trino como principio y fundamento trascendente de la historia de la salvación”, en Mysterium Salutis II. Cristiandad, Madrid 1977, 324-328; ibíd., "Trinidad”, en K. Rahner (dir.), Sacramentum Mundi VI. Herder, Barcelona 1976², 744-745.

37 K. RAHNER: Curso fundamental sobre la fe, 97-98.

38 Al respecto, Rahner aclarará el término persona y sus distintas acepciones que pueden inducir a error; cfr. K. RAHNER: Curso fundamental sobre la fe, 342.

39 Cfr. G. ZARAZAGA: "La comunión trinitaria. La contribución de Karl Rahner", Estudios Eclesiásticos, vol. 80, nº 313 (2005), 281-282.

40 En este sentido, Rahner señala que «Dios no es otro "junto" a los hombres. Es lo más íntimo, el núcleo y centro esencial del hombre amado, es más íntimo que la íntima irreferibilidad, que la última cerrazón en sí del hombre», K. RAHNER: "Consagración del laico para la cura de almas”, en ibíd., Escritos de Teología III. Taurus, Madrid 1961, 305. 
autocomunicación de Dios con el apelativo de ontológica ${ }^{41}$. No obstante esta constatación, Rahner asume la dificultad de comprensión que implica para el hombre el reconocimiento de la realidad personal de Dios. Al respecto, señala que «la frase "Dios es persona" sólo puede decirse de Dios y es verdadera si, al decir y entender esta frase, la arrojamos a la obscuridad inefable del misterio sagrado» ${ }^{42}$.

La realidad personal de Dios, a pesar de su autocomunicación, sigue siendo para el hombre un misterio, ya que su ser absoluto es superior a cualquier comprensión humana, por eso cualquier reflexión siempre será incapaz de contener dicha realidad o de siquiera expresarla, pues siempre se corre el riesgo de atribuir arbitrariamente un contenido a dicha frase. Para superar dicho peligro Rahner plantea el camino del reconocimiento de la presencia de Dios en la experiencia histórica del hombre, por eso propondrá que, como auténticos filósofos, hemos de permitir que «la experiencia histórica nos dé el contenido de este enunciado formal, y así dejamos que Dios sea persona tal como él quiere salirnos al encuentro y nos encuentra de hecho en la historia individual, en la profundidad de nuestra conciencia y en la historia entera de la humanidad» ${ }^{43}$.

Así, el ser personal de Dios se presenta como una realidad inaccesible de manera inmediata a la razón natural; ya que el hombre se encuentra con un misterio que le resulta incomprensible. Rahner plantea la necesidad de reconocer a Dios en su ser personal, tal como él es; y, a la vez, Dios se hace reconocible para el hombre cuando asume su ser categorial y, desde allí, reconoce la presencia de Dios en su existencia, asumiendo la presencia de Otro que es indisponible para él ${ }^{44}$.

41 Este aspecto queda claramente expresado por Rahner cuando señala que «Cuando hablamos de la comunicación de Dios mismo, no podemos entender esta palabra como si Dios en una revelación cualquiera dijera algo sobre sí mismo. La palabra 'comunicación de Dios mismo' (autocomunicación) quiere significar realmente que Dios en su realidad más auténtica se hace el constitutivo más íntimo del hombre. Se trata, pues, de una autocomunicación ontológica de Dios. De todos modos, el término 'ontológica' —ésta es la otra parte de una posible confusión- no puede entenderse en un sentido meramente objetivista, a manera de una cosa», K. RAHNER: Curso fundamental sobre la fe, 147-148.

42 K. RAHNER: Curso fundamental sobre la fe, 99.

43 Ibíd.

44 La condición histórica y categorial del ser humano es un aspecto central en la autocomunicación planteada por Rahner, cfr. G. ZARAZAGA: Trinidad y comunión. La teología trinitaria de K. Rabner y la pregunta por sus rasgos hegelianos. Secretariado Trinitario, Salamanca 1999, 269-270. 


\subsection{Trinidad: expresión del don absoluto de Dios}

Una vez constatada la realidad personal de Dios, ahora se abordará la forma cómo la Trinidad participa de la autocomunicación, lo que permitirá entender tanto su carácter absoluto como también su carácter trinitario. Se comienza este recorrido bajo la premisa que el mismo Rahner establece en cuanto que no hay diferencia entre Dios en sí y Dios para nosotros, en el sentido que uno sería el ser de Dios y otro distinto sería el que se revela a los hombres, ya que para Rahner la realidad de Dios sólo se puede descubrir en la experiencia trascendental del hombre, por lo que los enunciados que de ella emanan no pueden tener esta doble dimensión ${ }^{45}$.

A partir de esta premisa, se puede comprender la concepción de Rahner en torno a la Trinidad inmanente y a la Trinidad económica, que para él ambas son la misma ${ }^{46}$, ya que sostiene firmemente que la Trinidad que el ser humano conoce es aquella que se ha revelado en la historia de la salvación y es la misma que se denomina Trinidad inmanente; de este modo, manifiesta que no hay diferencia entre ambas nomenclaturas trinitarias ${ }^{47}$.

Hay que consignar que frente a la comprensión de la Trinidad inmanente, Rahner llama a tener precaución respecto a la doctrina psicologista de la Trinidad que busca explicar lo que es ella en sí, prescindiendo de la experiencia histórico-salvífica ${ }^{48}$, lo que es un riesgo, puesto que dicha experiencia es la única realidad con la que cuenta el ser humano para referirse a la Trinidad.

Por todas estas razones, Rahner sostiene la identificación entre Trinidad inmanente y económico-salvífica, señalando la función que realiza cada persona divina en la automanifestación histórica de Dios:

en tanto la forma de darse Dios a nosotros como Espíritu, Hijo y Padre no significa la misma forma de darse, por cuanto en la manera de comunicarse

\footnotetext{
45 Cfr. K. RAHNER: "Sobre la posibilidad de la fe hoy", en ibíd., Escritos de Teología V. Taurus, Madrid 1964, 15; ibíd., "Revelación", en K. Rahner (dir.), Sacramentum Mundi VI. Herder, Barcelona 19782, 94.

46 El planteamiento trinitario de Rahner es visto como el más original de la teología moderna pues tiene «ante los ojos la tensión que en la historia de la teología se ha dado entre el pensamiento metafísico y el histórico-salvífico, se decide por un sentido absolutamente histórico-salvífico», B. GROM y J. R. GUERRERO: El anuncio del Dios cristiano. Análisis y consecuencias para la educación de la fe. Secretariado Trinitario, Salamanca 1970, 47.

47 Cfr. K. RAHneR: “Trinidad”, 737-738.

48 Cfr. K. RAHNER: "Advertencia sobre el tratado dogmático De Trinitate”, en ibíd., Escritos de Teología IV. Taurus, Madrid 1963, 114-115.
} 
a nosotros hay diferencias verdaderas y reales, estas tres formas de darse a nosotros han de distinguirse estrictamente. "Para nosotros" el Padre, el Logos-Hijo y el Espíritu inicialmente son los mismos. Mas en tanto estas formas de darse a nosotros el único y mismo Dios no pueden suprimir la autocomunicación real de Dios como el Dios uno, único y mismo, las tres maneras de donación del único y mismo Dios han de corresponderle a él, el uno y mismo, en él mismo y para él mismo ${ }^{49}$.

Rahner presenta a las personas trinitarias como maneras o formas de donación de Dios para nosotros, ellas se han de distinguir perfecta y claramente, ya que cada una cuenta con características únicas e inconfundibles, esto hace que el hombre las experimente como distintas y diferentes; pero, en su esencia Dios es único y el mismo. En este punto, se puede apreciar que la idea de absoluto se remite a la esencia de Dios, ello permite que se pueda reconocer como elemento constitutivo de la autocomunicación de Dios. Por eso cada una de estas formas de donación que le corresponden a Dios mismo, no son meras representaciones o modos de conocer la divinidad, sino que son expresiones reales de Dios ${ }^{50}$.

Así, cuando Rahner se refiere al Espíritu Santo lo presenta como aquel que realiza la salvación en el hombre, produciendo en éste efectos divinizantes, no de manera externa y ajena a su realidad, sino que se instala en el centro más íntimo de su existencia; esto se realiza en todos y cada uno de los seres humanos, ninguno escapa a esta acción divina, pues la autocomunicación de Dios es un momento constitutivo del hombre ${ }^{51}$. Es tan profunda esta acción del Espíritu Santo, que le da la posibilidad de participar en la naturaleza divina, elevándolo para que se desarrolle este encuentro profundo entre Dios y la creatura ${ }^{52}$.

En la perspectiva de la Trinidad económica, el encuentro entre Dios y el hombre se desarrolla también por medio del Hijo, el cual se manifiesta para los seres humanos de una manera singular y concreta. En este contexto, Jesucristo no es un emisario que representa a Dios a manera de una imagen, sino que él es Dios mismo que por medio de su

\footnotetext{
49 K. RAHNER: Curso fundamental sobre la fe., 170.

50 La novedad del pensamiento de Rahner es que comprende la Trinidad desde la autocomunicación de manera que se trata de una absoluta unidad que se comunica mediante las tres personas a la historia de la humanidad, cfr. M. LUCCHETTI, "Um Deus para ser amado. Algumas reflexões sobre a doutrina trinitária em Karl Rahner", Perspectiva Teologica, vol. 36, nº 98 (2004), 125-141.

51 La profesora Kilby presenta este tema en el apartado donde presenta a Cristo y la gracia, cfr. K. KILBY: Introducción a Karl Rabner, 35-50.

52 Cfr. K. RAHneR: “Gracia”, en K. Rahner (dir.), Sacramentum Mundi, III. Herder, Barcelona 1976², 325.
} 
vida y de su entrega amorosa por el hombre manifiesta de una forma histórica concreta que el amor de Dios ha sido entregado para los hombres incondicionalmente ${ }^{53}$.

Estas constataciones llevan a Rahner a afirmar que también el hombre puede acceder a una noción de Dios como Padre ${ }^{54}$. El Padre sería aquel a quien se designa con el apelativo Dios, pues se le atribuyen aspectos absolutos como ser inefable o misterio sagrado y porque también es reconocido como fundamento y origen inabarcable de la revelación que se realiza por medio del Hijo y del Espíritu Santo ${ }^{55}$.

De esta manera, las manifestaciones de Dios hacia el hombre son las que permiten conocerlo a partir de su actuación en la historia, de modo que es en su dimensión económico-salvífica que se trasluce su realidad inmanente, reconociendo la plenitud de la divinidad una, la única y misma esencia divina ${ }^{56}$. A partir de esto se puede afirmar que es Dios mismo quien se autocomunica al hombre personalmente, de modo que no es una simple figura:

Por tanto, la afirmación: El Dios uno y mismo está dado para nosotros como Padre, Logos-Hijo y Espíritu Santo, o bien: El Padre mismo se nos da en absoluta autocomunicación por el Hijo en el Espíritu Santo, ha de oírse y pronunciarse como afirmación sobre Dios tal como éles en sí mismo, pues de otro modo no sería en el fondo ninguna afirmación sobre la autocomunicación de Dios $^{57}$.

53 Una de las características más reconocidas del pensamiento trininitario de Rahner es su fuerte acento cristológico que se ve atravesado por el hecho de la encarnación, cfr. A. Cordovilla: "La teología es pensar. La relación entre teología y filosofía en K. Rahner", 405.

$54 \mathrm{Al}$ respecto, es interesante hacer notar la precaución que Zarazaga menciona con respecto a la identificación de Dios con el Padre, porque según él se corre el riesgo de no diferenciar al Dios que se accede por medio de la revelación natural con aquél revelado por Jesucristo; a la vez, la naturaleza divina podría aparecer como atribuida sólo al Padre y no al resto de las personas trinitarias, cfr. G. ZARAZAGA: Trinidad y comunión. La teología trinitaria de K. Rahner y la pregunta por sus rasgos hegelianos, 266.

55 Este aspecto de su pensamiento lo expresa Rahner más detalladamente en Mysterium Salutis, al afirmar que: "Cuando decimos 'Dios' no presuponemos una teología trinitaria 'latina' (contraponiéndola a la 'griega'), sino la que nos da la Biblia (y si se quiere, la teología griega). Dios es aquí el 'Padre', eso es, el Dios absolutamente sin origen, siempre sabido como presupuesto, que se comunica a sí mismo, precisamente en cuanto que, por una parte, su comunicación no coincide simplemente con él en una identidad sin vida, y por otra, sigue siendo en esta comunicación el ser sin origen, libre, inabarcable, que no se vacía nunca», K. RAHNER: "Dios trino como principio y fundamento trascendente de la historia de la salvación", 313-314.

56 Cfr. K. RAhner: "Naturaleza y gracia", en ibíd., Escritos de Teología IV. Cristiandad, Madrid 1977, 229.

57 K. RAHNER: Curso fundamental sobre la fe., 170. 
El ser humano no tiene acceso directo a la Trinidad inmanente, sólo se accede a Dios trinitariamente por su expresión económico-salvífica y esta manifestación es la puerta de acceso a la vida intratrinitaria. Rahner, poniendo de manifiesto que la Trinidad económico-salvífica es la misma inmanente, aclara que todo aquello que se puede decir de Dios por su manifestación en la historia, también se puede afirmar de Dios en su vida intradivina ${ }^{58}$. Gracias a esta manifestación es posible acceder a la intimidad divina y vislumbrar que la experiencia de la autocomunicación de Dios se da en primer lugar en sí mismo ${ }^{59}$, lo cual nos permite comprender de mejor manera la autocomunicación de Dios hacia los hombres.

\section{A modo de conclusión}

Como hemos visto, Rahner designa a Dios como absoluto, he aquí la razón fundamental por la que atribuye a la autocomunicación un carácter absoluto, pues si el emisor de ésta es absoluto en sí mismo y, por lo mismo, tiene atributos absolutos, dicha autocomunicación no puede sino ser absoluta. Este punto se aprecia de una sencillez sin igual, puesto que se presenta como obvio que siendo Dios el absoluto, realice actos absolutos y, en este caso, su autocomunicación sea absoluta.

Pero hemos de decir que no es tan sencillo, ya que existen diversas formas de abordar el tema del absoluto. De este modo, si Dios es declarado absoluto desde una perspectiva filosófica que concibe al absoluto como aquel que no puede en ninguna medida relacionarse con otro, sea lo que sea, entonces no podríamos pensar en Dios como el emisor de la autocomunicación puesto que no podría entrar en relación alguna con un receptor de ella. Pero si consideramos a Dios como un absoluto que es capaz de autocomunicarse, de trascenderse a sí mismo, para donarse en una autocomunicación, donde lo que se entrega es él mismo, entonces estamos frente a una nueva comprensión del absoluto, que en este caso es Dios. En esta segunda postura podemos ubicar a Rahner.

Partiendo de la afirmación anterior, podemos hacer algunas precisiones en lo que se refiere a las consecuencias de presentar a Dios como el absoluto que se despliega plenamente a sí mismo en su autocomunicación. Lo primero es que dicho término hace referencia a

58 Esta identificación es desarrollada extensamente en K. RAHNER: “Advertencia sobre el tratado dogmático De Trinitate", 117-136.

59 Cfr. K. RAHNER: “Trinidad”, 738-743. 
una donación que Dios mismo hace de sí, lo que nos permite apreciar que el empleo del concepto de autocomunicación asociado a la condición o carácter de absoluto, da cuenta de una realidad plena en la que Dios se despliega hacia el hombre con un amor total. En segundo lugar, en el encuentro entre Dios y el hombre se da una realidad sorprendente, Dios sigue manteniendo su autonomía ontológica, es decir, sigue siendo Dios y el hombre sigue siendo lo que es, una creatura, que en la medida que se realiza el encuentro, se descubre y desarrolla más plenamente.

En este sentido, es notable constatar que el hecho de haber considerado la autocomunicación de Dios desde su carácter absoluto, nos ha dado un horizonte más amplio hacia el cual enfocar nuestra mirada, pues si bien es cierto se consiguió lo que pretendíamos, es decir, focalizar el amplio espectro de la autocomunicación para, de este modo, acceder a una mejor comprensión del mismo, hemos de decir que ello nos ha abierto una serie de nuevas posibilidades en lo que se refiere a la comprensión del término. Por ejemplo, a partir de la importancia que Rahner entrega a la encarnación se ve ratificado el carácter histórico de la autocomunicación, ya que en la historia de la salvación relatada en la Sagrada Escritura ya se da cuenta de una cercanía real entre Dios y los hombres; además el teólogo alemán señala que Dios se manifiesta en la creación y en cada hombre, es por este motivo que la manifestación plena en Jesús expresa a los hombres el carácter absoluto de la autocomunicación de Dios, pues es un acontecimiento único, irrepetible e irrevocable.

El planteamiento trinitario de Rahner permite dar una nueva comprensión al carácter absoluto de la autocomunicación de Dios, pues la sinergia que se da entre la comprensión de la Trinidad inmanente y trascendente permite tener una mejor visión del misterio para el ser humano. Este aspecto queda claro cuando se aprecia el valor soteriológico que Rahner destaca de la manifestación de cada una de las personas trinitarias pues, de este modo, acerca el misterio mismo de Dios a la existencia de cada uno de los seres humanos. A partir de ello se puede apreciar que el Dios absoluto, presentado por Rahner, no es un ser abstracto, lejano e inalcanzable; sino más bien un Dios cercano, que busca y propicia un encuentro personal con el hombre que se fundamenta en su amor absoluto.

Por último, se debe hacer una mención especial a la forma cómo Rahner utiliza el concepto de absoluto, pues, como planteamos en la introducción, él no pretende en el Curso fundamental sobre la fe desarrollar el carácter absoluto de la autocomunicación de Dios, para contraponerlo al relativismo imperante en nuestra sociedad, pues lo presenta como este 
ser que dona el ser a sus creaturas y que se convierte en el desde dónde y el hacia dónde de la experiencia trascendental del hombre, con lo cual se aprecia que directamente no enfrenta al relativismo. Pero no podemos dejar de mencionar que, de cara a esta dependencia radical del hombre hacia Dios, el ser humano se reconoce como un ser trascendente capaz de reconocer que su vida está orientada a otro que le es indisponible y que está más allá de él mismo y es en esta circunstancia de su existencia que el planteamiento del Ser absoluto como aquel que dona la existencia y como aquel que se autocomunica al hombre para manifestarle la plenitud de su existencia a la que está llamado, ciertamente se opone al relativismo, pues la vida del hombre se desarrolla en esta tensión paradojal de saberse inmerso en un mundo que es relativo y limitado, pero a la vez reconocerse como llamado a una plenitud que nunca se verá plenificada si se empantana en los seres relativos de su entorno, es por ello que una y otra vez el hombre ha de ser consciente de su estar referido a Dios.

Sumario: 1. Dios absoluto, fundamento de la autocomunicación absoluta; 1.1. Dios absoluto; 1.2. Atributos absolutos de Dios; 1.2.1. Ser absoluto; 1.2.2. Misterio absoluto; 1.2.3. Sujeto absoluto; 2. El carácter trinitario de la autocomunicación absoluta; 2.1. Dimensión personal del Dios absoluto; 2.2. Trinidad: expresión del don absoluto de Dios; A modo de conclusión. 